\title{
Study on Correlating Properties of Cement Paste and Concrete
}

\author{
Sreekumar K K ${ }^{1}$, Dr.Elson John ${ }^{2}$, Indu Susan Raj ${ }^{3}$ \\ ${ }^{1}$ Dept. of Civil Engineering, Mar Athanasius College of Engineering, Kerala, India \\ ${ }^{2}$ Asst. Professor, Dept. of Civil Engineering, Mar Athanasius College of Engineering, Kerala, India \\ ${ }^{3}$ Asst. Professor, Dept. of Civil Engineering, Mar Athanasius College of Engineering, Kerala, India
}

\begin{abstract}
Concrete is a composite material consisting of aggregates, binding material, water and admixtures. It is the most widely used construction material on earth. This paper is a study on loss of workability, setting time, property correlation between paste and concrete for various admixture and superplasticiser dosages. The mineral admixtures considered are Fly ash and (Ground granulated blast furnace slag) GGBS with superplasticiser Masterglenium SKY 8233. The flow analysis in paste can be used as a guideline for finding saturation superplasticiser dosage. The study on setting time shows than results of paste and concrete are comparable. It is also found that saturated superplasticiser dosage in paste and concrete can be correlated for better compressive strength. By this study, tests on the paste can be used as guide for optimising flow behaviours, setting time, compressive strength in concrete without doing tedious tests in concrete.
\end{abstract}

Keywords - Compatibility, Marsh cone Time, Retention time, Saturation dosage.

\section{INTRODUCTION}

Concrete is the most widely used construction material on earth. An additive or admixture is a material added into the concrete in small quantities to give desirable properties to the concrete. Admixtures in concrete confer some beneficial effects such as acceleration, retardation, air entrainment, water reduction, plasticity etc. To understand the consequences of admixture- cement interactions, and to optimize the functional properties of admixtures, appropriate descriptions of their mode of action must be developed. This paper is an effort to study paste fluidity, concrete compressive strength, correlation of paste and concrete setting time in the presence of chemical admixture Masterglenium SKY 8233 and mineral admixtures- fly ash and GGBS.

\subsection{Cement}

\section{EXPERIMENTAL DETAILS}

The cement used was Deccan Cements. The following are the various test results conducted as per IS:12269-1987 to determine the physical properties of this cement.

\begin{tabular}{|c|l|c|}
\hline S1.No. & \multicolumn{1}{|c|}{ Properties } & Values \\
\hline 1. & Specific gravity & 3.125 \\
\hline 2. & Standard consistency & $30 \%$ \\
\hline 3. & Initial setting time(in minutes) & 75 \\
\hline
\end{tabular}

\subsection{Fine aggregate}

Manufactured sand was used as fine aggregate for the experiments. Various tests were conducted to determine the properties of sand. Grading is the particle size distribution of an aggregate as determined by sieve analysis and the taken fine aggregate belongs to zone II. The sieve analysis was done as per IS:2386 (Part-1)1963. The sieve analysis and properties are shown in table below. 


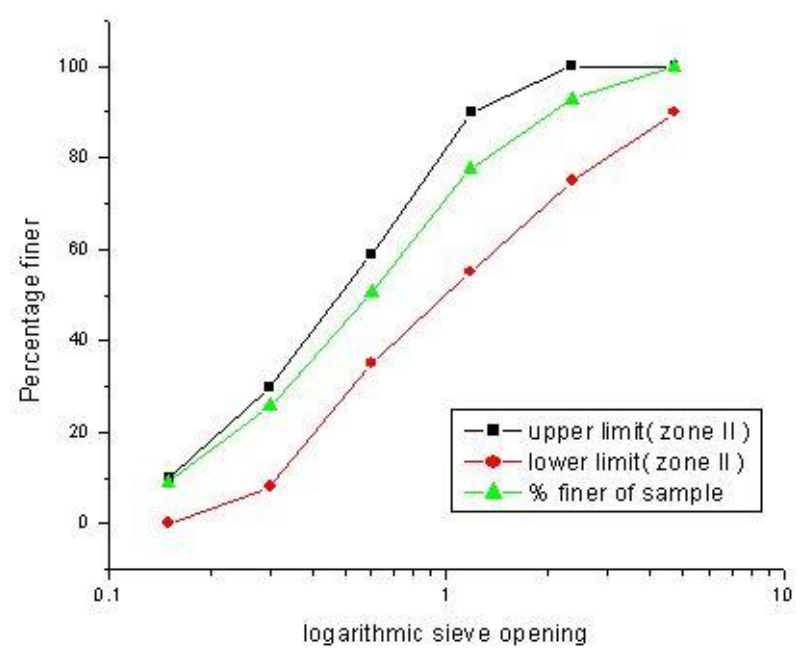

\begin{tabular}{|c|c|c|}
\hline Sl.No. & Properties & Values \\
\hline 1. & Specific gravity & 2.66 \\
\hline 2. & Fineness modulus & 3.442 \\
\hline 3. & Water absorption & $10 \%$ \\
\hline
\end{tabular}

\subsection{Coarse aggregate}

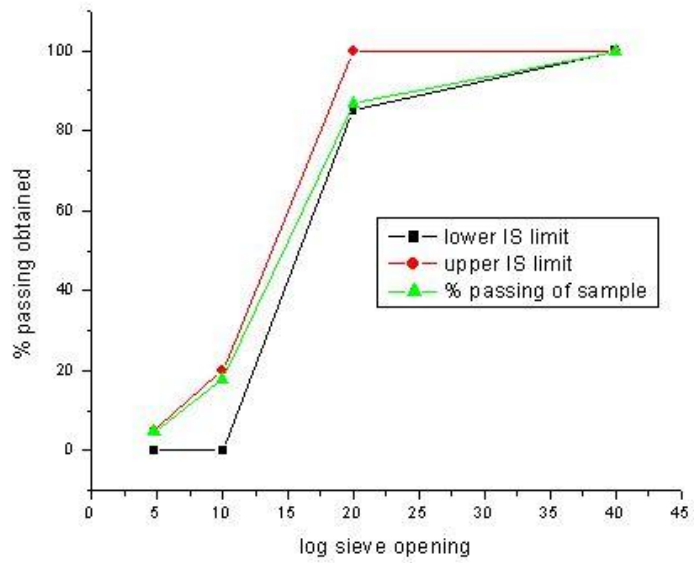

\begin{tabular}{|c|c|c|}
\hline S1.No. & Properties & Values \\
\hline 1. & Specific gravity & 2.77 \\
\hline 2. & Fineness modulus & 2.596 \\
\hline 3. & Water absorption & $2.3 \%$ \\
\hline
\end{tabular}

\section{TESTING PROCEDURE}

\subsection{Tests on paste}

\subsubsection{Marsh cone test}

The marsh cone test is a workability test used for specification and quality control of cement pastes. The time needed for $1000 \mathrm{ml}$ to $500 \mathrm{ml}$ paste volume to flow out of a standard size cone is recorded which is linked to fluidity. For pastes, a metal cone of $8 \mathrm{~mm}$ nozzle diameter was employed. according to European EN 445 standard. The longer the flow time, lower is the fluidity. A graph can be prepared for log time and dosages of super plasticizer. The dose at which the $\log \mathrm{T}$ vs Superplasticizer dosage curve makes an angle $140 \pm 10^{\circ} \mathrm{C}$ is the saturation point. If we increase the content of Super plasticizer more than saturation point it does not affect 
much to the time. The dose is the optimum dose for that brand of cement, mineral admixture and super plasticizer for selected $\mathrm{w} / \mathrm{b}$ ratio.

\subsubsection{Mini slump test}

The mini-slump test was done to measure the consistency of cement paste. The mini-slump cone has a bottom diameter of $38 \mathrm{~mm}$, a top diameter of $19 \mathrm{~mm}$, and a height of $57 \mathrm{~mm}$. The cone is placed in the center of a square piece of glass on which the diagonals and medians are traced. The cone is lifted and after one minute, the average spread of the paste, as measured along the two diagonals and two medians, is recorded. This test was done to find out the range of superplasticiser dosage having an influence on the fluidity.

\subsubsection{Vicat penetration Test}

Vicat apparatus consists of plunger of $10 \mathrm{~mm}$ dia, measuring cylinder, weighing balance, weight box and trowel. In this paper vicats apparatus is used to study the setting nature of cement paste containing various admixtures at optimum superplasticiser dosage. The graph showing penetration reading versus time can be used for predicting the nature of setting in concrete.

\subsection{Tests on fresh concrete}

\subsubsection{Slump Test}

Slump is a measure indicating the workability of cement concrete. A slump test apparatus consisting of slump cone which is in the form of a hollow frustum made of thin steel sheet and tamping rod placed over a base plate. Fresh concrete is filled in 4 layers with each layer tamped 25 times. Subsidence of the concrete after removing the cone is measured and should be ensured within the limits as per the mix design.

\subsubsection{Penetrometer Test}

Penetrometer is an instrument used to find setting time of concrete by measuring the penetration resistance. Needles (of area $645,323,161,65,32$ and $16 \mathrm{~mm} 2$ ) penetrating the concrete can be changed as time elapses. In this test initial setting time is the elapsed time after initial contact of cement and water, required for the mortar (sieved from the concrete using IS $4.75 \mathrm{~mm}$ sieve) to reach a penetration resistance of $3.43 \mathrm{~N} / \mathrm{mm} 2$. And final setting time is the elapsed time after initial contact of cement and water, required for the mortar ( sieved from the concrete using IS $4.75 \mathrm{~mm}$ sieve ) to reach a penetration resistance of $26.97 \mathrm{~N} / \mathrm{mm} 2$.

\subsection{Tests on hardened concrete}

\subsubsection{Test for compressive strength}

The test was conducted as per IS: 516 -1959. At least three specimens, preferably from different batches, shall be made for testing to avoid error in the result. The specimen should be surface dry before testing. The specimens were tested in digital compression testing machine of capacity $5000 \mathrm{kN}$. The testing results can be used to find the effect of admixture addition in compressive strength of concrete.

\section{METHODOLOGY}

- Preliminary material testing study such as standard consistency, initial setting time, final setting time, specific gravity are done in cement paste.

- Finding the optimum dosage of superplasticiser in control mix using mini slump and marsh cone tests. Both tests are done combinely in same sample to validate each others results and to eliminate insignificant dosages of superplasticiser for testing under various percentages of admixture mixes lately.

- Finding the marsh flow curve for various significant dosages of superplasticiser in cement paste mixes with Fly ash 25\%,30\%,35\% and GGBS 35\%, 40\%, 45\%, 50\%. Test is conducted at 5 minute and 60 minute for checking loss of fluidity of paste.

- Finding concrete slump and cube compresive strength for M30 mix with various admixture and superplasticiser dosage.

- Effect of admixture and superplasticiser dosages on setting time of cement paste can be done using Vicats penetration instrument and that of concrete can be studied using Penetrometer.

- Effect of admixture and superplasticiser dosages on cube compressive strength also studied. 


\section{RESULTS AND DISCUSSIONS}

\subsection{Saturation dosage and loss of fluidity of cement paste mixes}

Marsh cone and mini slump tests were carried out on the cement for different admixture dosages at w/c ratio of 0.45 . The saturation dosage of superplasticizer for the control mix is obtained as $0.2 \%$ at 5 min and $0.25 \%$ at $60 \mathrm{~min}$ from both the tests which validates the result. The plot of flow time/spread versus superplasticiser dosage shows a distinct change of slope at superplasticiser dosage beyond which there is no distinct difference in flow time or spread. This is recognised as saturation dosage.
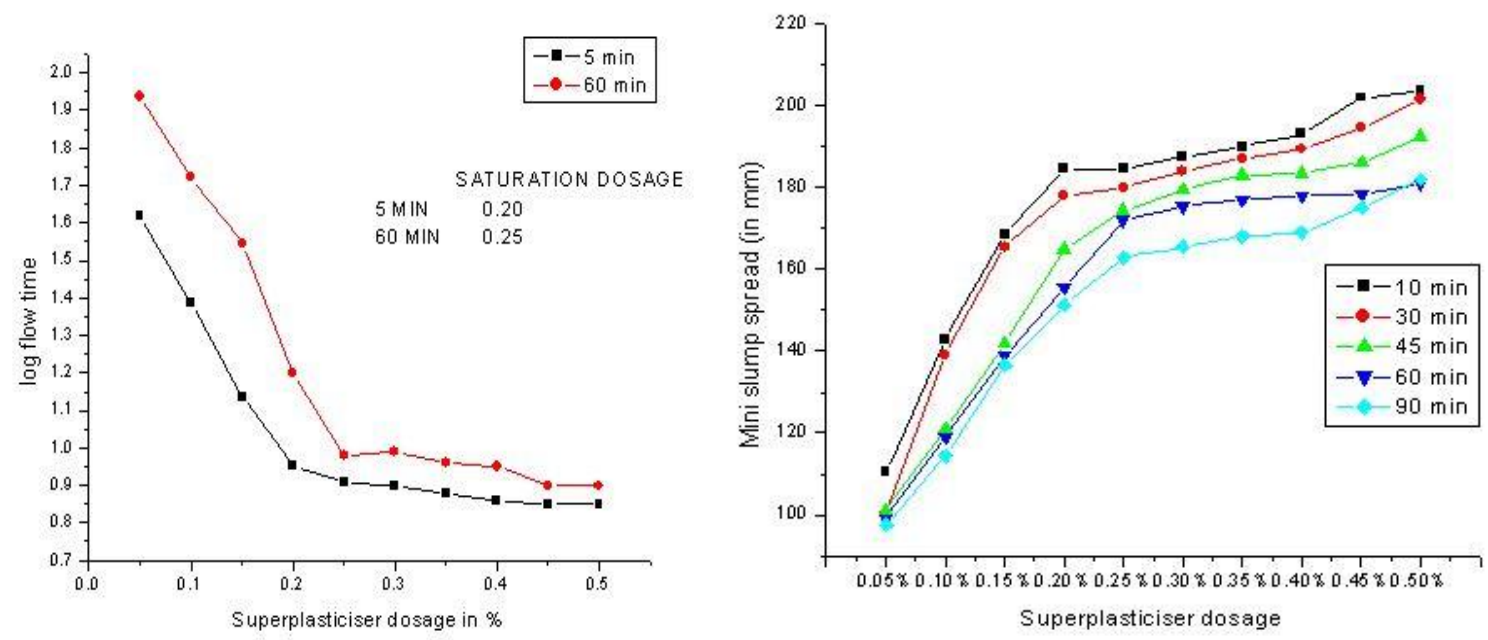

Fig 1 (a) Marsh flow curve from 1000 to $500 \mathrm{ml}$ for control mix (b) Mini slump spread plot for control mix
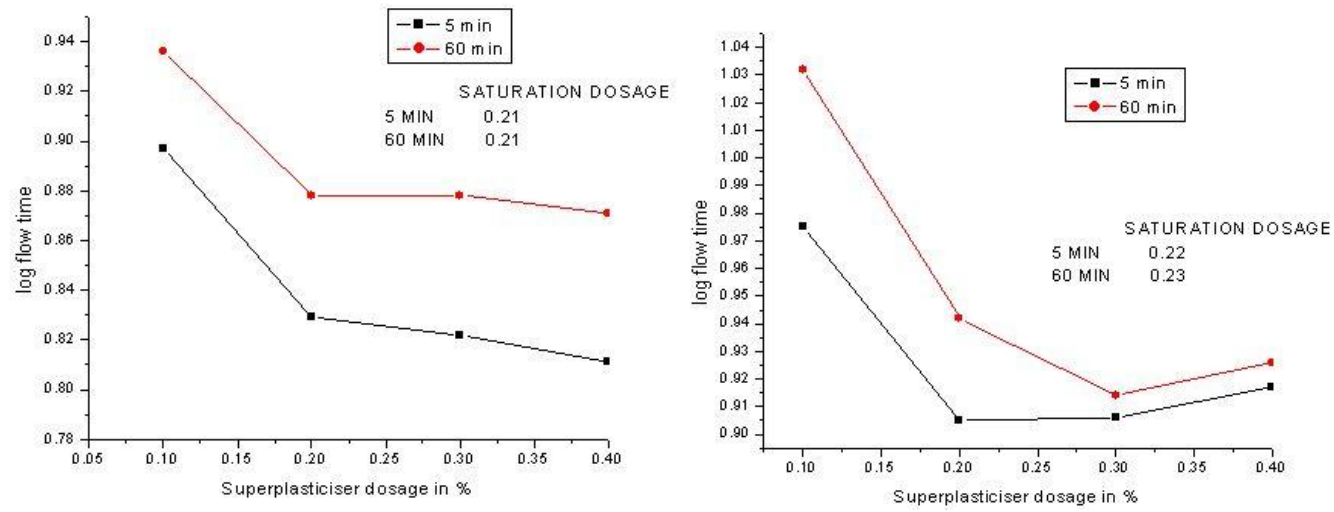

Fig 2 (a) Marsh flow curve of GGBS 35\% paste mix (b) Marsh flow curve of GGBS 40\% paste mix
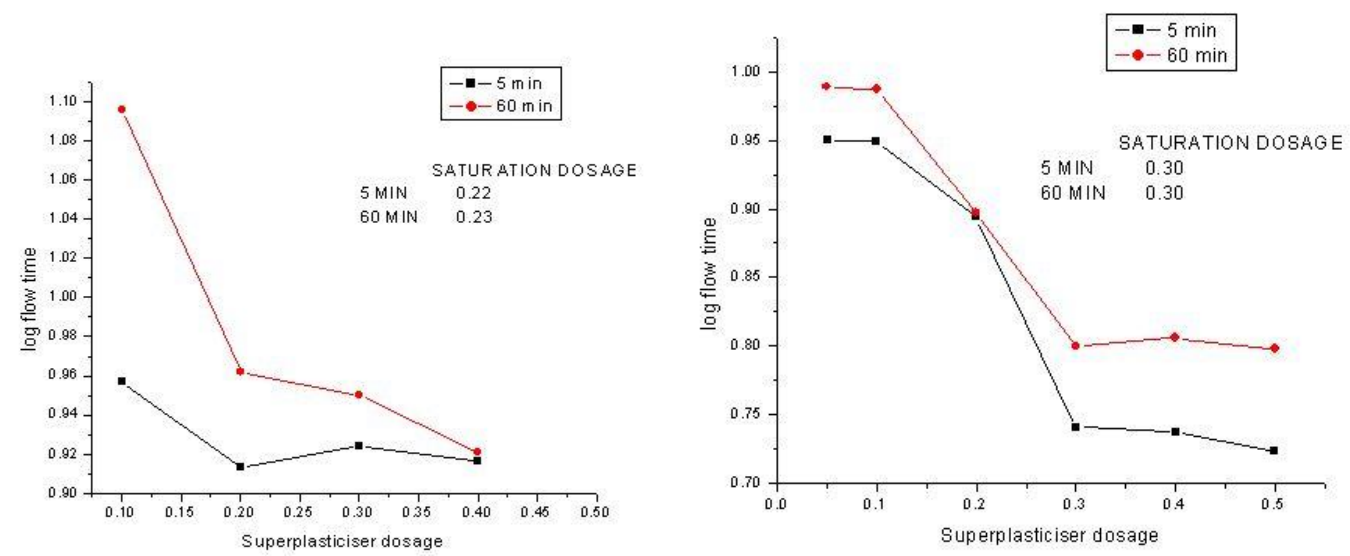

Fig 3 (a) Marsh flow curve of GGBS 45\% paste mix (b) Marsh flow curve of GGBS 50\% paste mix 

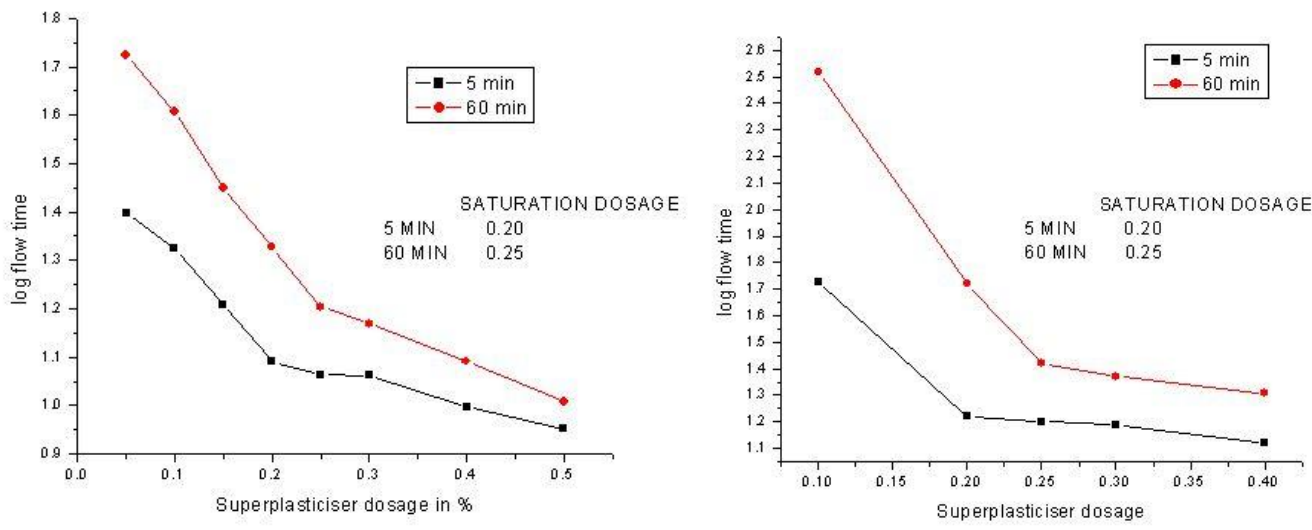

Fig 4 (a) Marsh flow curve of flyash 25\% paste mix (b) Marsh flow curve of flyash 30\% paste mix
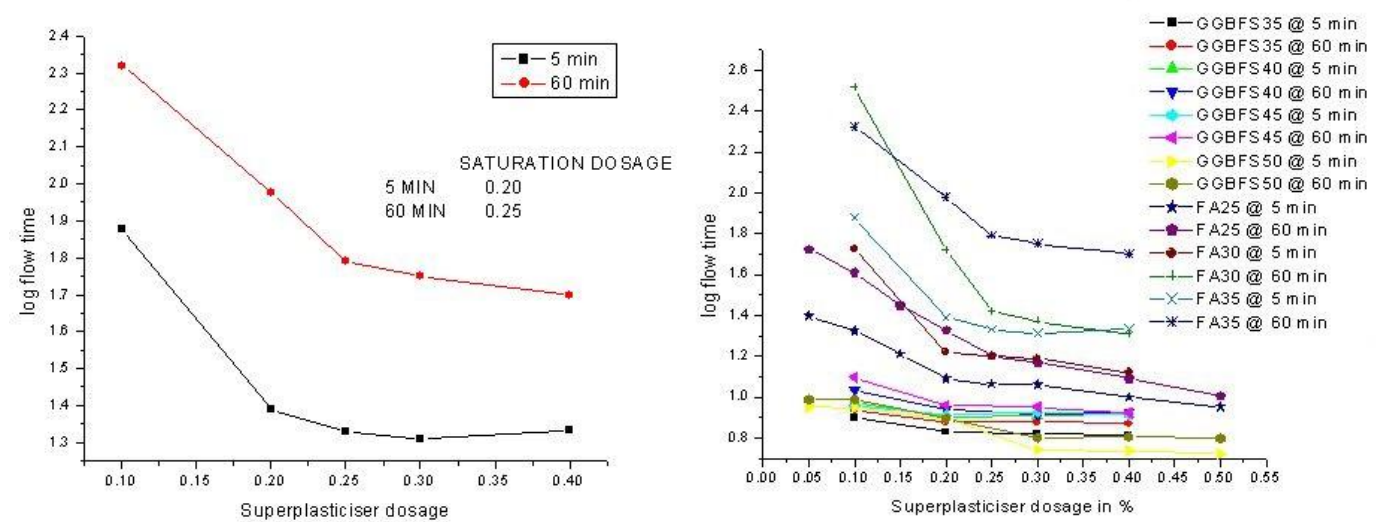

Fig 5 (a) Marsh flow curve of flyash 35\% paste mix (b) Loss of fluidity

The change in the flow behaviour of fresh paste was measured at $5 \mathrm{~min}$ and $60 \mathrm{~min}$ after mixing. Before testing, the paste was kept in an airtight container at $27^{\circ} \mathrm{C}$. For testing, it was taken out of the container and mixed for 15 seconds.

Fig 5(b) gives the Marsh cone flow-time curves at $5 \mathrm{~min}$ and at $60 \mathrm{~min}$ after mixing. It can be seen that both the 60 minute line and the 5 minute line show decrease in flow times with increasing superplasticiser dosage upto saturation dosage. Beyond saturation dosage the flow time do not change much because of settling of cement particles in the paste.

With reference to 5 minute line, a shift to the right in 60 minute line shows loss of fluidity. The saturation dosage of superplasticiser increases with time. The saturation dosages are higher at $60 \mathrm{~min}$ than those at $5 \mathrm{~min}$. This can be attributed to the increase in surface area of the hydrated cement particles with the newly formed hydrates encapsulate the superplasticiser.

Fig 5(b) shows the difference in flow time between 5 and 60 min curves is higher at lower superplasticiser dosage, with comparable levels of fluidity being achieved at 60 minutes only for various dosages of fly ash. By overdosage of plasticiser beyond the 5 minute saturation point can reduce the loss of fluidity in fly ash mix . But for GGBS comparable levels of fluidity is achieved at 5 and 60 minutes before and after saturation dosage of 5 minutes. The high fluidity loss at low dosages can be attributed to rapid flocculation and inadequate dispersion of cement particles at less than saturation dosage. In ready-mixed concrete, the fluidity of the paste after 60 minutes is more significant than immediate fluidity $(5 \mathrm{~min})$. The saturation dosage corresponding to $60 \mathrm{~min}$ should be used in mix design rather than arbitrarily dosing the superplasticiser to maintain workability. 
The following conclusions can be derived from the graphs:

- Marsh flow time decreases with increase in superplasticiser dosage due to increased flow of paste showing increase in workability.

- Beyond saturation dosage (data point at which $140 \pm 10^{\circ}$ is obtained in marsh flow curve) no significant change in fluidity is observed.

- Fly ash does not affect the fluidity of the paste because saturation dosage at $5 \mathrm{~min}$ is $0.2 \%$ and at $60 \mathrm{~min}$ $0.25 \%$ is maintained for all the three fly ash dosages like $25 \%, 30 \%, 35 \%$ and control mix.

- The fluidity of fly ash mixes decreases after 1 hour. This is indicated by the significant shift of the $60 \mathrm{~min}$ flow curve to the right of 5 min flow curve of the same mix .

- The fluidity of GGBS mix do not change significantly for 35-45\% after 1 hour.

- Fluidity of various GGBS mixes have similar saturation dosages.

- The difference of fluidity is large at lower superplasticiser dosage and the difference narrows down with the increase in superplasticiser dosage.

- The loss of fluidity after $60 \mathrm{~min}$ is highest for fly ash 35\% mix and all GGBS mixes $35-45 \%$ have significantly less loss of fluidity.

\subsection{Effect of superplasticiser dosage on setting of cement paste and concrete}
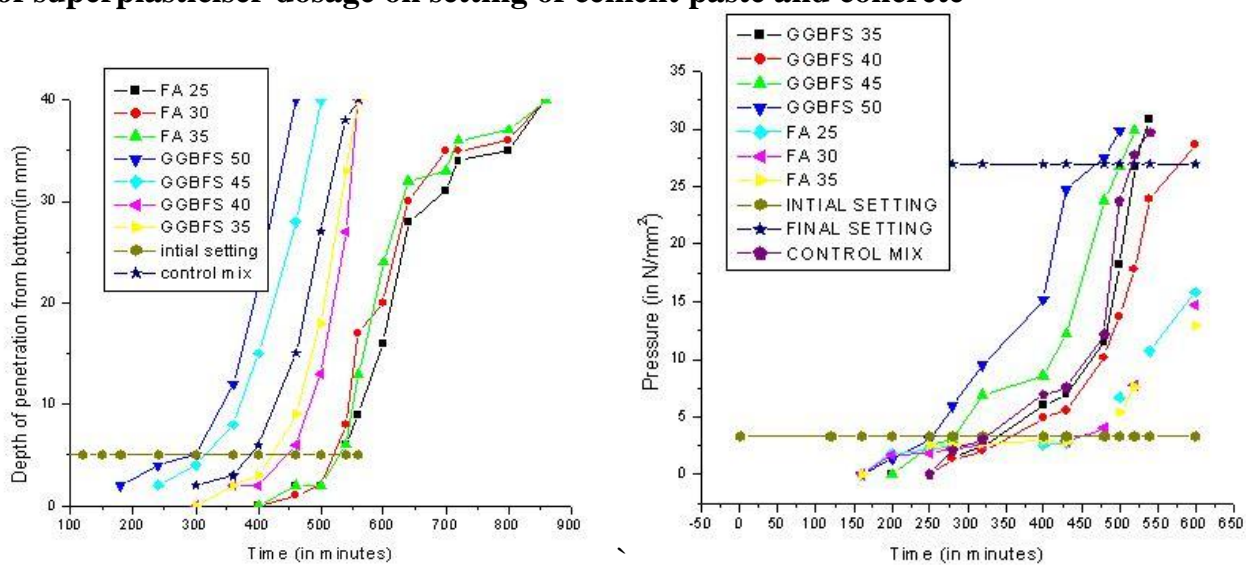

Fig 6 (a) Vicat penetration measurements of cement paste for various mixes at superplasticiser saturation dosage (b) Penetrometer measurements of concrete for various mixes at superplasticiser saturation dosage

The cement paste setting is retarded because the presence of superplasticizer slows down the rate of hydrating and dissolving ions. The Vicats apparatus was used to determine the setting time of superplasticised cement paste. The paste was prepared using a mortar mixer, with a w/c of 0.45 at the saturation dosage of superplasticiser. Fig 6(a) shows the beginning $(5-7 \mathrm{~mm}$ Vicat penetration) and end of setting (40 mm Vicat penetration) for each superplasticiser at saturation dosage.

Following are the conclusions obtained from the graph:

- Setting time of Fly ash based mix is significantly higher than GGBS based mix.

- GGBS 35 and 40 mixes have prolonged setting duration than control mix while GGBS 45 and 50 sets faster than control mix.

- GGBS 50 is found to have the lowest setting time comparitievely.

The time between beginning and end of setting is 3 to 4 hours. This shows that the superplasticiser delays the setting and alite hydration. However, the effect diminishes when alite hydration sets in.The setting time of concrete was determined following IS 8142-1976. The concrete was sieved through a $4.75 \mathrm{~mm}$ IS sieve. The sieved material (mortar) was tested, and the results obtained are as shown in Fig 6(b). The time to penetrate resisting $3.43 \mathrm{~N} / \mathrm{mm}^{2}$ and $26.97 \mathrm{~N} / \mathrm{mm}^{2}$ were taken as the initial and final setting times respectively. The initial and final setting time for GGBS based concrete were 4 hours and 8 hours respectively and initial setting time for Fly Ash based concrete was 7 hours. The final setting time for Fly Ash based concrete was beyond 10 hours because the formation of $\mathrm{C}_{3} \mathrm{~S}$ responsible for early strength takes time. At GGBS 35 and $40 \%$ the setting occurs in a similar manner but a bit prolonged with same initial and final setting times. As the dosage of GGBS increases beyond $40 \%$ the setting time reduces significantly beyond control mix for $45 \%$ and $50 \%$. However, the difference between initial and final setting times was about 4 hours in both paste and concrete. Both the vicat 
penetration test on the paste and the penetration resistance test on mortar measure setting by determining the degree of stiffness.

\subsection{Effect of superplasticiser dosage on compressive strength of concrete}

Table 1 shows concrete compressive strength with different admixture mixes. The strength of superplasticised concrete at 28 days is more than that of the reference concrete. The design strength of 38.25 $\mathrm{N} / \mathrm{mm}^{2}$ is attained in the reference concrete and lower dosages $35 \%$ and $40 \%$ of GGBS. Beyond 40 percentage addition of GGBS, strength reduces but stays within the the target mean strength, the highest strength being achieved at GGBS 40 mix. The compressive strength of Fly ash based concrete is less than target mean strength because it can be said that fly ash concrete has less initial strength and attains strength in a later stage. It can be observed that the strength of concrete depends upon admixture and superplasticiser dosage based on the combination compatability. However, superplasticiser dosages above saturation causes bleeding, stiffening and reduced strength.

Table 1 Compressive strength of concrete for different mixes

\begin{tabular}{|c|c|c|c|c|c|}
\hline $\begin{array}{c}\text { Admixture } \\
\text { dosage } \\
\text { \%) }\end{array}$ & $\begin{array}{c}\text { Saturation } \\
\text { dosage of } \\
\text { superplasticiser } \\
\text { in cement paste } \\
\text { at 60 min }\end{array}$ & $\begin{array}{c}\text { Saturation dosage } \\
\text { of superplasticiser } \\
\text { in cement concrete }\end{array}$ & $\begin{array}{c}\text { Slump } \\
\text { (in mm) }\end{array}$ & $\begin{array}{c}\text { 28 day } \\
\text { Compressive } \\
\text { strength in } \\
\text { MPa }\end{array}$ & $\begin{array}{c}\text { Correlation } \\
\text { number for } \\
\text { SP dosage }\end{array}$ \\
\hline M30 control mix & 0.25 & 0.38 & 78 & 39.28 & 1.52 \\
\hline GGBS 35 & 0.21 & 0.42 & 82 & 41.73 & 2 \\
\hline GGBS 40 & 0.23 & 0.44 & 95 & 42.61 & 1.91 \\
\hline GGBS 45 & 0.23 & 0.47 & 90 & 41.58 & 2.04 \\
\hline GGBS 50 & 0.3 & 0.55 & 85 & 39.88 & 1.83 \\
\hline FA 25 & 0.25 & 0.41 & 80 & 34.26 & 1.64 \\
\hline FA 30 & 0.25 & 0.40 & 86 & 34.1 & 1.6 \\
\hline FA 35 & 0.25 & 0.41 & 92 & 33.82 & 1.55 \\
\hline
\end{tabular}

VI. CONCLUSIONS

The investigation here is only a basic study on the loss of workability, setting time, property correlation between paste and concrete. An extensive literature survey was conducted on the topics related to correlation of properties of paste and concrete. The objectives, scope of this study and tests are finalised.

The first stage dealt with the determination of optimum dosage of superplasticiser in various admixture dosage mixes by analysing the results of marsh cone test. The second stage is to find the effect of admixture dosage in setting time of cement paste and concrete. The third stage is to find the effect of admixture dosage on slump and cube compressive strength of concrete. The study led to the following conclusions:

1. The marsh cone test provides the comparative flow behaviour of superplasticised pastes and allows defining a saturation dosage. Therefore, it can be used in selecting superplasticiser type and dosage.

2. The saturation dosage obtained for concrete is slightly higher than that for cement paste due to superplasticiser adsorption by the fines present in the aggregate.

3. The flow behaviour of pastes at 60 minutes after mixing shows significant fluidity loss in mixes with various dosages of Flay Ash while GGBS show comparitievely less loss of fluidity. If the fluidity of superplasticised paste at 60 minutes or at other duration is to be targeted rather than the immediate fluidity, the corresponding saturation dosage should be used in the mix design rather than arbitrarily overdosing the superplasticiser.

4. The Vicat test results show that the setting behaviour depends on the dosage of admixture and the setting time is higher for Fly ash based concrete than GGBS based concrete. The setting of Fly ash based concrete is far greater than the control mix. GGBS $35 \%$ and $40 \%$ have delayed the setting time than control mix whereas GGBS $45 \%$ and 50\% have significantly reduced setting time with GGBS 50\% sets at a faster rate. A comparison of the Penetrometer and Vicat test results on concrete and paste respectively indicates that the trend in setting with respect to different admixture dosages is practically the same in both cases. Hence the tests done in paste can be taken as a reference in selecting admixture dosage for concrete. The study confirms that GGBS admixture dosage have an effect on the time difference between initial and final setting times based on the superplasticiser considered here.

5. Desired compressive strength of mixes can be achieved by using saturated superplasticiser dosage in concrete equivalent to saturation dosage of superplasticiser in cement paste at 60 min multiplied by Correlation number. Correlation number for GGBS can be in range 1.83-2.04 and for Fly ash in range 1.55-1.64 for the admixture dosages considered. 


\section{REFERENCES}

[1]. M. Sonebi, M. Lachemi, K.M.A. Hossain, Optimisation of rheological parameters and mechanical properties of superplasticised cement grouts containing metakaolin and viscosity modifying admixture, Construction and Building Materials, Vol. 65, 2014, pp $566-573$.

[2]. Costas A. Anagnostopoulos, Effect of various superplasticisers on the physical and mechanical properties of cement grout, Procedia Engineering,Vol. 122, 2015, pp 39 - 46

[3]. Haibo Xie, O. Burciaga Diaz, J.I. Escalante Garcia, Workability and proportion design of pumping concrete based on rheological parameters, Construction and Building Materials, Vol. 24, 2010, pp 1166-1175.

[4]. Mohammed Maslehuddin, Ji ri Zacha, Azra Korjenicb, Jitka Hroudovaa, Effect of key mixture parameters on flow and mechanical properties of reactive powder concrete, Energy and Buildings, Vol. 58, 2013, pp 319-323.

[5]. Shuang Liu, Ali Jihad Hamad, Preparation, microstructure and rheological properties of asphalt sealants for bridge expansion joints, International Journal of Advanced Engineering Applications, Vol 7,2014, pp 52-57.

[6]. M.I.A. Khokhar, E. Roziere , P. Turcry , F. Grondin, A. Loukili, Mix design of concrete with high content of mineral additions: Optimisation to improve early age strength, Proceedings of the 6th Asia Pacific Structural Engineering and Construction conference, Malaysia, 2006.

[7]. Viktor Mechtcherine, Mosleh Salman, Lec. Sawsan Akram Hassan, Optimisation of the rheological and fracture mechanical properties of light weight aggregate concrete, Journal of Engineering and Development, Vol.14, No.4, 2010

[8]. Jihad Hamad Mohammad, Ali Jihad Hamad, A classification of lightweight concrete: materials, properties and application review, International Journal of Advanced Engineering Applications, Vol 7,2014, pp 52-57.

[9]. Mahrshwarappa S. M, Madhuvan S., Chetan Kumar K. M., J.K. Dattatreya, Effect of superplastiziers compatibility on the workability, early age strength and stiffening characteristics of OPC, PPC and PSC pastes and mortar, International Journal of Research in Engineering and Technology, vol. 3, May 2014

[10]. Syed Allah Bakash and B. Krishna Reddy, Increasing the sustainability of concrete by using superplasiziers- A study, International Journal of Advanced Structures and Geotechnical Engineering, Vol- 2, January 2013

[11]. IS: 4031 (Part-I)-1988, Indian Standard Code of Practice for methods of physical tests for Hydraulic cement, Bureau of Indian Standards, New Delhi,1997

[12]. IS 12269-1987 Indian Standard Specification for 53 grade ordinary Portland cement, Bureau of Indian Standards, New Delhi, 1997.

[13]. Elson John and Revindra Gettu, Effect of Temperature on the flow properties of Superplasticized cement paste, ACI Materials Journal.

[14]. Jayasree Chakkamalayath and Ravindra Gettu, Correlating properties of paste, mortar and concrete, ACI Materials Journal.

[15]. M.S Shetty, Concrete Technology - Theory and Practice, S. Chand and Company Ltd, New Delhi

[16]. IS 456:2000, Indian Standard Code of plain and reinforced concrete, Bureau of Indian Standards, New Delhi.

[17]. IS1199:1959, Indian Standard Code of Methods of sampling and analysis of concrete, Bureau of Indian Standards, New Delhi.

[18]. IS 516:1959, Indian Standard -Methods of tests for strength of concrete, Bureau of Indian Standards, New Delhi.

[19]. IS: 2386(Part III)-1963 Indian standard-Method of testing for aggregates for concrete-Part-III specific gravity, density, voids, absorption and bulking, Bureau of Indian standard, 1997, New Delhi.

[20]. IS: 2386(Part I)-1963 Indian standard-Method of testing for aggregates for concrete-Part-I particle size and shape, Bureau of Indian standard, 1997, New Delhi.

[21]. IS: 4031 (Part 3)-1988 Indian standard- Methods of physical tests for hydraulic cement, Bureau of Indian standard, 2002, New Delhi.

[22]. IS: 4031 (Part 4)-1988 Indian standard- Methods of physical tests for hydraulic cement-Determination of consistency of standard cement, Bureau of Indian standard, 2002

[23]. IS: 4031 (Part 5)-1988 Indian standard- Methods of physical tests for hydraulic cement-Determination of initial and final setting time, Bureau of Indian standard, 2002

[24]. IS : 8142 - 1976 ,Indian standard - Method of test for determining setting time of concrete by penetration resistance, Bureau of Indian Standards, New Delhi.

[25]. IS 10262 : 2009, Concrete mix proportioning - guidelines(first Revision), Bureau of Indian Standards, New Delhi.

[26]. IS: 383-1970, Specification for coarse and fine aggregates from natural sources for concrete, (Second Revision), Bureau of Indian Standards, New Delhi.

[27]. IS: 516-1969, Methods of test for strength of concrete, (Second Revision), Bureau of Indian Standards, New Delhi.

[28]. IS: 1458-2000, Compression testing machine used for testing of cement and mortar, (Second Revision), Bureau of Indian Standards, New Delhi. 